\title{
Buen gobierno y sociedades cooperativas: Disposiciones y recomendaciones para el buen gobierno de las sociedades cooperativas
}

Good governance and cooperative societies: provisions and recommendations for the good governance of cooperative societies

Bom governo e sociedades cooperativas: disposições e recomendações para o bom governo das sociedades cooperativas

Recibido: 1 de agosto de 2018

Aceptado: 19 de septiembre de 2018

Publicado: 5 de abril de 2019

Cómo citar este artículo: Sánchez-Pachón, L. (2019). Buen gobierno y sociedades cooperativas: Disposiciones y recomendaciones para el buen gobierno de las sociedades cooperativas. Cooperativismo \& Desarrollo, 27(1), 1-30. DOI: https://doi. org/10.16925/2382-4220.2019.01.10

\section{Luis Ángel Sánchez Pachón*}

Artículo de investigación. https://doi.org/10.16925/2382-4220.2019.01.10 Este trabajo es resultado del proyecto de investigación "Economía Social, Autogestión y Empleo" (DER2016-78732-R) financiado por el Ministerio de Economía, Industria y Competitividad del Gobierno de España y por el Fondo Europeo de Desarrollo Regional.

* Doctor en Derecho por la Universidad de Valladolid (España). Profesor Contratado Doctor de Derecho Mercantil. Facultad de Ciencias Económicas y Empresariales. Universidad de Valladolid.

Correo electrónico: pachon@eco.uva.es.

https://orcid.org/0000-0002-2990-368X 


\section{RESUMEN:}

La preocupación por el Buen gobierno corporativo no ha estado ausente en el sector cooperativo. Muchas de las disfuncionalidades que se apuntan en la estructura y funcionamiento de las cooperativas son comunes en el ámbito de empresas societarias del sector privado capitalista, aunque, evidentemente, lo sean bajo parámetros diferentes. Conviene, por ello, examinar las propuestas sobre gobierno corporativo (corporate governance), que, aunque centradas en el gobierno de las sociedades cotizadas, se han venido elaborando en los últimos años, impulsadas por los cambios operados en la realidad económica y social. Ahora bien, en este análisis resulta prioritario conocer la perspectiva o enfoque de buen gobierno corporativo que se siga (accionarial o monista versus pluralista o Stakeholders), así como la técnica jurídica que se proponga (intervención legislativa versus autorregulación a través de los que se conoce como Códigos de Buen Gobierno).

En el trabajo que presentamos, después de perfilar algunos aspectos conceptuales, describimos cómo se han incorporado al Derecho español las ideas del gobierno corporativo, destacamos las principales etapas en esa búsqueda de la construcción del buen gobierno societario y analizamos algunas propuestas concretas de buen gobierno que, desde distintos ámbitos, se han dirigido, especialmente, a las sociedades cooperativas.

PALABRAS CLAVE: Gobierno corporativo; Shareholders; Stakeholders; grupos de interés; Código de buen gobierno.

\section{Summary}

The concern for good corporate governance has not been absent in the cooperative sector. Many of the problems pointed out in the structure and functioning of cooperatives are common within private equity firms, although they are evidently under different parameters. It is therefore appropriate to examine the proposals on corporate governance, which, although centralized in the governance of listed companies, have been elaborated in recent years, driven by changes in economic and social reality. In this analysis, it is a priority to know the perspective or approach of good corporate governance that follows (shareholder or monistic vs. pluralist or stakeholders), as well as the proposed legal technique (legislative intervention versus self-regulation through which one knows as Codes of Good Government). In this paper, after outlining some conceptual aspects, we describe how the ideas of corporate governance have been incorporated into Spanish law; we highlight the main steps in the search for the construction of good corporate governance and analyze some concrete proposals of good governance that, from different scopes, have been directed, in particular, to cooperative societies.

Keywords: corporate governance; shareholders; stakeholders, interest groups, Code of Good Government.

\section{Resumo}

A preocupação pelo bom governo corporativo não tem estado ausente no setor cooperativo. Muitos dos problemas apontados na estrutura e no funcionamento das cooperativas são comuns no âmbito de empresas societárias do setor privado capitalista, ainda que, evidentemente, o sejam sob parâmetros diferentes. Convém, por isso, examinar as propostas sobre governo corporativo (corporate governance), que, embora centralizadas no governo das sociedades cotadas, vêm sendo elaboradas nos últimos anos, impulsionadas pelas mudanças operadas na realidade econômica e social. Nesta análise, resulta prioritário conhecer a perspectiva ou a abordagem de bom governo corporativo que siga (acionista ou monista versus pluralista ou stakeholders), bem como a técnica jurídica proposta (intervenção legislativa versus autorregulamentação por meio das quais se conhece como Códigos de Bom Governo). Neste trabalho, após traçar o perfil de alguns aspectos conceituais, descrevemos como as ideias do governo corporativo têm sido incorporadas ao Direito espanhol; destacamos as principais etapas na busca da construção do bom governo societário e analisamos algumas propostas concretas de bom governo que, de diferentes âmbitos, têm sido dirigidas, em especial, às sociedades cooperativas.

Palavras-chave: governo corporativo; shareholders; stakeholders, grupos de interesse, Código de Bom Governo 


\section{INTRODUCCIÓN.}

En un mundo en transformación, crecientemente competitivo y globalizado, el mantenimiento de unadecuado nivel de desempeño empresarial exigea las empresas el despliegue de estrategias en múltiples frentes (financiero, tecnológico, organizativo...), que tienen su punto de conexión en el modelo de gobierno corporativo. El mayor desafío teórico y empresarial sigue siendo la búsqueda de modelos institucionales óptimos de gobierno de las empresas, a través de nuevas regulaciones, de Códigos de conducta de asunción voluntaria, de cambios institucionales internos (Chaves y Schediwy, 2004, p. 5). Si las empresas del sector privado capitalista -y en particular grandes sociedades anónimas- necesitan de un Buen gobierno corporativo, esa misma aspiración alcanza, también, a otras entidades, a otros agentes y operadores económicos cualquiera que sea la naturaleza o forma jurídica que revistan (Mateu de Ros, 2007, p. 57).

La búsqueda del Buen gobierno corporativo se ha reactivado en los últimos años como una respuesta indispensable para afrontar nuevas situaciones. A la preocupación no ha sido ajeno el movimiento cooperativo. Muchas de las disfuncionalidades que se apuntan en la estructura y funcionamiento de las cooperativas son comunes en el ámbito de empresas societarias del sector privado capitalista, aunque, evidentemente, lo sean bajo parámetros diferentes. La sociedad cooperativa, como después precisaremos, ha podido padecer también en algunos casos ciertas deficiencias en el funcionamiento del gobierno cooperativo: reducción de la participación de los socios en las asambleas de grandes cooperativas; nombramiento de directivos asalariados poco competentes o desligados de los socios; falta de capacidad técnica o deficiente información de los miembros del Consejo Rector; ausencia de rotaciones; carencia de mecanismos de control o supervisión, deficiencias e inseguridades en los sistemas de responsabilidad; déficit de trasparencia... Afortunadamente no estamos ante tendencias generalizadas en todo el sector ni en todos los tipos de cooperativas. Sin embargo, el examen de algunas prácticas societarias (Paz, 1995, 28-29) y los resultados de algunas investigaciones realizadas en España (Romero, 2002, 201-202; Romero, 2006; Mozas, 2004, 167 y ss.; Mozas, et al., 2005; Buendía, 2000), nos indican, por ejemplo, que el modelo de gobierno democrático presenta disfuncionalidades que pueden alcanzar, de una u otra manera, a las entidades.

Todos estos datos revelan la conveniencia de examinar las propuestas que sobre el gobierno corporativo (corporate governance), que, aunque centradas en el gobierno de las sociedades cotizadas, se han venido elaborando en los últimos años, impulsadas por los cambios operados en la realidad económica y social, y que en el Ordenamiento jurídico español, en esta última etapa, han cristalizado, por una parte, 
en la Ley 31/2014, de 3 de diciembre, por la que se modifica la Ley de Sociedades de Capital para la mejora del gobierno corporativo y, por otra, en el Código de Buen Gobierno de las sociedades cotizadas, aprobado por Acuerdo del Consejo de la Comisión Nacional del Mercado de Valores -CNMV- de 18 de febrero de 2015.

Ahora bien, esas propuestas de buen gobierno corporativo estarán condicionadas, por un lado, por la idea, perspectiva o enfoque de gobierno corporativo que siga. Como después precisaremos, tradicionalmente ha predominado el enfoque accionarial, monista podríamos decir, basado en la soberanía de los accionistas en el gobierno de la empresa (shareholders), pero no puede ignorarse -y, en nuestra opinión, menos aún en el ámbito de las sociedades cooperativas- las teorías que proponen el gobierno de la empresa desde la consideración de otros grupos de interés (stakeholders), más o menos amplios, que permiten hablar de modelos pluralistas (Esteban, 2005, p. 27).

Por otra parte, tampoco cabe ignorar que esas propuestas vendrán a ser el resultado del principal debate técnico-jurídico - no exento de viva polémica doctrinal- en torno los instrumentos o mecanismos para la consecución de los objetivos del buen gobierno. En la elección de esa sistemática subyace, evidentemente, una importante concepción político-jurídica. El dilema que tradicionalmente se ha planteado en el buen gobierno corporativo en torno a la intervención legislativa (regulación) versus autorregulación también ha de valorarse, en nuestra opinión, cuando se quiera abordar el logro del buen gobierno de las sociedades cooperativas.

Las distintas iniciativas promovidas en los derechos nacionales por los gobiernos de los estados y por los operadores económicos entorno al buen gobierno corporativo no dejan de ser reflejo de ese dilema. Por un lado, la idea que el mercado es capaz de impulsar, por sí mismo, el buen gobierno corporativo (lo que conlleva la desregulación y simplificación legislativa), confiando en una autorregulación a partir de simples recomendaciones de carácter voluntario. Por el otro lado, la invocación a la intervención legislativa, reclamando un espacio para el legislador como principal agente impulsor del buen gobierno corporativo. El resultado de este debate ha venido siendo una especie -en palabras el profesor Embid Irujo (2016, p. 20)- de "doble regulación", en la que va a ser frecuente, la presencia de normas imperativas pero, también, las modernas recopilaciones de recomendaciones de carácter voluntario.

La convivencia entre los dos sistemas organizativos no es siempre fácil, dando lugar a conflictos y contradicciones como consecuencia de las divergencias entre los preceptos legales y las recomendaciones de carácter voluntario. Probablemente la solución a ese conflicto pase no tanto por contraponer autorregulación y regulación legal societaria, sino por considerar los dos instrumentos complementarios, que de forma coordinada pueden dar resultados mucho más satisfactorios, eficaces y 
equitativos que si se hace una apuesta exclusiva por uno de ellos (Emparanza, 2012, p. 165).

En definitiva, como viene a recoger Montalenti (2015, pp. 2-3), en la consecución de una corporate governance eficaz y eficiente, la mezcla de legislación primaria, reglamentos de autoridad de vigilancia, códigos de autodisciplina y códigos éticos se afirma como instrumento típico en todos los ordenamientos avanzados. Así, también, en los Principes de gouvernance d'entreprise del G20 et la OCDE (2017, p. 13), se viene a reconocer que un gobierno eficaz de la empresa exige un marco jurídico integrado normalmente por la ley, reglamentaciones, mecanismos de autodisciplina, compromisos voluntarios y prácticas corporativas que son el producto de circunstancias, historia y tradiciones de cada país. Tratándose, así, de buscar el equilibrio deseable entre las disposiciones legislativas, las regulaciones, autodisciplina, estándares voluntarios, etc.

Evidentemente, tampoco se trata de trasladar al ámbito de las sociedades cooperativas, pura y simplemente, ni las normas legales imperativas ni las recomendaciones de aquel Código de Buen Gobierno. Esas normas y recomendaciones en el Derecho español se han pensado y están destinadas para las sociedades cotizadas. Como se ha podido decir "no es posible trasladar de forma automática a las sociedades cooperativas los planteamientos de buen gobierno diseñados para las sociedades de cotizadas" (Santos, 2014, p. 339). Se trata más bien de que, sin desconocer los puntos básicos comunes en el logro del buen gobierno corporativo, pensemos en proponer respuestas específicas para el caso cooperativo, preservando y fortaleciendo la identidad cooperativa. Como se ha dicho, también, el acercamiento de las normas aprobadas en relación con las sociedades cooperativas al régimen jurídico de las sociedades de capital, pese a resultar positivo en ciertos casos, debe hacerse con cautela y teniendo en cuenta las singularidades de estas sociedades (Vázquez, 2018, p. 1015).

En las páginas que siguen, después de perfilar algunos aspectos conceptuales, describimos cómo se ha llevado a cabo la incorporación al Derecho español de las ideas del buen gobierno. Analizamos las principales etapas de esa búsqueda de la construcción del buen gobierno societario, hasta culminar en la Ley de 31/2014 y el Código de buen gobierno de la sociedades cotizadas aprobado por la CNMV. Finalmente, destacamos algunas de las propuestas de buen gobierno que, desde distintos ámbitos, se han dirigido, especialmente, a las sociedades cooperativas. 
6 Buen gobierno y sociedades cooperativas: Disposiciones y recomendaciones para el buen gobierno

\section{LA CONCEPTUACIÓN DEL BUEN GOBIERNO CORPORATIVO DESDE DISTINTOS ENFOQUES.}

El Gobierno corporativo viene siendo un tema recurrente, también en la literatura y en los analistas españoles, particularmente, desde los últimos años del siglo pasado. El tema sin embargo, no es nuevo. Tradicionalmente, el Gobierno corporativo se ha ligado a la teoría de la agencia (Garicano y Hafner, 2016, p. 9) y a los problemas entre accionistas (principales) y directivos (agentes). La temática podría incluso enlazarse con el parecer de Adam Smnith al referirse a la administración de las compañías por acciones. Pero también pueden descubrirse otros antecedentes no tan lejanos reveladores de enfoques o perspectivas más amplios de gobierno corporativo que, como más adelante precisaremos, hoy no pueden ignorarse (Rodríguez, 2006, pp. 10 y ss.). Desde la aparición de las grandes sociedades de propiedad accionarial dispersa, el gobierno empresarial no ha dejado de preocupar en la literatura jurídica y económica (Garrido, 2007, p. 40; Velasco, 2006, p. 665; Farrando, 2006, pp. 167 y ss.). Sin embargo, esa literatura lo ha abordado, predominantemente, desde un enfoque financiero o accionarial, es decir, desde el enfoque que busca cubrir las expectativas de los accionistas de la empresa. La preocupación se ha reactivado en los últimos años. Continuándose con la misma tarea de búsqueda de una respuesta indispensable para afrontar la nueva problemática asociada al fenómeno de la globalización (Fernández, 2017, pp. 465 y ss.). Si bien, esa tarea se sigue haciendo, básicamente salvo ligeros matices, desde ese mismo enfoque accionarial.

A la preocupación por el buen gobierno corporativo no ha sido ajeno el movimiento cooperativo, incluido el español. Si bien, hoy por hoy, sin los resultados normativos que se han producido en las sociedades de capital, en particular, en las sociedades cotizadas. Esa preocupación se ponía de manifiesto ya con el Informe de la Comisión de Investigación de ACl-Europa sobre gobierno corporativo y sistemas de control de los directivos en las cooperativas europeas, donde se revelaban importantes deficiencias en el modelo del gobierno cooperativo (Volkers y Lees, 1996). A esas deficiencias se pudieron sumar otros signos preocupantes en la evolución del movimiento cooperativo, que han sido objeto de atención por nuestros comentaristas (Chaves, 2004 a; Chaves, 2004 b). Así, se pudieron señalar, como deficiencias en el funcionamiento del gobierno cooperativo, la reducción de la participación de los socios en las asambleas; el nombramiento de directivos asalariados incompetentes, o desligados de los socios y con miras exclusivas en su progreso personal; la falta de capacidad técnica de los miembros del Consejo Rector, la deficiente información, 
la falta de capacidad crítica por su vinculación con la dirección, la ausencia de rotaciones; carencias, en definitiva, que hacen difícil que puedan desempeñar una eficaz tarea de supervisión (Chaves, 2004, a, p. 38).

\subsection{La conceptuación del buen gobierno corporativo desde el enfoque monista.}

Existen muchas definiciones de gobierno corporativo o gobierno societario (Farrando, 2006, 158; Mateu de Ros, 2004, 26; Garicano y Hafner, 2016, p. 9), aunque generalmente suelen apuntar, con mayor o menor amplitud, a los mismos elementos (Garrido, 2007, 44). A veces se destaca lo que de sistema implica, como paradigma de la evaluación del gobierno de las sociedades. Otras veces, se considera como el conjunto de mecanismos por los cuales la empresa es dirigida y controlada satisfactoriamente. De "sistema mediante el cual las empresas son dirigidas y controladas" hablaba la Comunicación de la Comisión Europea de 21 de mayo de 2003, sobre Modernización del Derecho de Sociedades y mejora de la gobernanza empresarial en la Unión Europea. Un plan para Avanzar. También como el conjunto de instrumentos que permiten resolver adecuadamente los distintos intereses de los que de forma directa o indirecta se ven afectados por la vida de la empresa.

Sin embargo, para una buena sistematización de esas definiciones conviene separar las dos perspectivas o enfoques de gobierno corporativo que mencionábamos al comienzo y que, evidentemente, determinan la misma conceptuación del buen gobierno.

Así, por un lado, el enfoque financiero, accionarial, monista o, también, de "principal-agente" (Shareholders), que tradicionalmente se ha ligado a la teoría económica de la agencia, parte de una visión reducida o simple del gobierno corporativo, donde el objetivo último es cubrir las expectativas de los accionistas (maximizar la riqueza de los accionistas).

Puentes, Velasco y Vilar (2009, p. 123) nos recogen algunas definiciones significativas que pueden englobarse en el enfoque accionarial. Como la definición de Shleifer y Vishny (1997): "El gobierno corporativo está relacionado con los medios a través de los cuales los financiadores de la empresa garantizan el rendimiento adecuado de sus inversores". De una forma más contundente estos mismos autores reducían el gobierno corporativo a el "Cómo los inversores consiguen que los gerentes les devuelvan su dinero". 
También en este enfoque se recoge la definición de Crespí y Gispert (1999): "Mecanismos que previenen o corrigen el posible conflicto de intereses entre directivos y accionistas".

Asimismo, dentro del primer enfoque pueden incluirse otras definiciones, como la de Cuervo (2004, p. 116): "El gobierno de la empresa tiene por finalidad el logro de la eficiencia en el uso de los activos y en los contratos que la configuran, para asegurar la creación de valor para los propietarios de los recursos financieros"; o la que viene a recoger García Álvarez (2012, pp. 185-186):

La noción de gobierno corporativo implica una serie de principios éticos y organizativos dirigidos a garantizar la transparencia de la información societaria, el cumplimiento de los deberes fiduciarios y en caso negativo la consiguiente responsabilidad de administradores, el funcionamiento eficaz de la sociedad como organización y la consecución de un equilibrio de poderes entre los administradores y los accionistas (pp. 185-186).

\subsection{La conceptuación del buen gobierno corporativo desde el enfoque pluralista.}

El enfoque pluralista o de partícipes (stakeholders) busca, sin embargo, el buen gobierno de la empresa teniendo en cuenta los grupos de interés o stakeholders de la empresa. Con este enfoque la teoría de la agencia se generaliza (se habla, incluso, de "multiagencia"). De esa manera los intereses financieros o de accionistas podrán ser considerados como un caso más, o, si se quiere, como un caso especial (Rodríguez, 2006, pp. 11; 17; 23). Este enfoque se asienta en la línea de investigación económica que viene cuestionando los argumentos económicos en los que descansa la teoría del modelo accionarial y la pretendida soberanía de los accionistas en el gobierno de la empresa cotizada (Moreno, 2015). El hecho de que los riesgos de la empresa no sean ya únicamente de los accionistas o propietarios del capital, sino de otros muchos colectivos (directivos, empleados, proveedores, clientes, consumidores, comunidades...), el hecho de que no solo los accionistas pueden considerarse inversores, el hecho de las externalidades negativas que generan las empresas obteniendo, a veces, beneficios a costa de determinados colectivos, son todos elementos que cuestionan los argumentos económicos en los que se ha venido basando el modelo accionarial. Así, desde esta perspectiva, como ha recogido (Moreno, 2015, p. 2), 
La empresa no puede ya considerarse como una simple asociación de capitales financieros, sino como una mucho más compleja agrupación de recursos (de capitales) de diferente orden (financieros, pero también físicos, humanos, cognoscitivos y relacionales), aportados por diferentes colectivos que cooperan en función de un interés común que trasciende al interés de cada grupo y que comparten en buena medida las características que la teoría convencional presupone sólo en los accionistas. Colectivos, en consecuencia, que pueden ser considerados en cierta forma también copropietarios de la empresa o, cuando menos, depositarios de derechos de gobierno en ella.

Puentes, Velasco y Vilar (2009, p. 123) incluyen, en este modelo pluralista, el concepto de gobierno corporativo de John y Senbet (1998): "Mecanismos por los que los stakeholders de una empresa ejercen el control sobre los internos y directivos de tal forma que sus intereses estén protegidos". También se incluyen otros conceptos, como el de Tirole (2001): "El diseño de instituciones que inducen o fuerzan a la dirección a interiorizar el bienestar de los stakeholders", y el de la OCDE (1999):

Sistema por el cual los negocios corporativos son dirigidos y controlados y donde se establecen derechos y obligaciones entre las diferentes personas involucradas en la empresa: propietarios, consejeros, administradores, accionistas y empleados, así como también las reglas y los procedimientos para la toma de decisiones sobre esos negocios.

Posteriormente, la versión de 2004 de la OCDE, se podrá traducir de la siguiente manera:

El gobierno corporativo abarca un conjunto de relaciones entre la administración de la empresa, su consejo de administración, sus accionistas y otras partes interesadas [grupos de interés]. También proporciona la estructura a través de la que se fijan los objetivos de la compañía y se determinan los medios para alcanzar esos objetivos y supervisar el desempeño" (Pedrejón, 2017, p. 95; Lizcano, 2016, p. 25).

En el prólogo a la edición de los Principes de gouvernance d'entreprise du G20 et de I'OCDE (2017) se reconoce que esos principios son fruto de la segunda revisión de los principios de gobierno corporativo, llevada a cabo en 2014/15. La Revisión se centró 
en la versión de 2004. Ésta es la que había dado cuerpo a la idea de que la transparencia, rendición de cuentas, supervisión del consejo de administración, respeto de los derechos de los accionistas y papel de los principales interesados, constituyen las piedras angulares de un sistema de gobierno corporativo que funciona bien. Concluyéndose ahora que esos ejes esenciales han sido consagrados y reforzados por las lecciones de la experiencia adquiridos desde 2004 y continúan otorgando a los principios su calidad, relevancia y su utilidad. Viniéndose a decir, más adelante, que

\begin{abstract}
El gobierno de la empresa hace referencia a las relaciones entre la dirección, su consejo de administración sus accionistas y otras partes interesadas. También determina, igualmente, la estructura por la cual se definen los objetivos de una empresa, así como los medios para alcanzarlos y para asegurar una vigilancia de los resultados obtenidos.
\end{abstract}

También, en el informe anual del Banco Central Europeo de 2004, en el glosario de términos, define el gobierno corporativo del modo siguiente:

\footnotetext{
Procedimientos y procesos con arreglo a los cuales se dirige y controla una organización. La estructura de gobierno corporativo especifica la distribución de derechos y responsabilidades entre las distintas personas que forman parte de la organización, como el consejo de administración, los directivos, los accionistas y otras partes interesadas, y establece las normas y procedimientos que se han de seguir en la toma de decisiones.
}

En fin, en el segundo de los enfoques también podrían incluirse otras muchas definiciones. Como resumen, por su concreción, podíamos recoger las definiciones extraídas del Libro Verde sobre normativa de gobierno corporativo de la Unión Europea, de 5 de abril de 2011: "Sistema por el cual las empresas son dirigidas y controladas y como una serie de relaciones entre el cuerpo directivo de una empresa, su consejo, sus accionistas y otras partes interesadas".

\title{
2.3. Enfoques en la conceptuación del buen gobierno corporativo de la sociedad cooperativa.
}

En el ámbito de la sociedades cooperativas, cuando se trata de perfilar la idea del buen gobierno en estas entidades, todo parece indicar que el enfoque predomínate ha de ser un enfoque pluralista. Fuera de este enfoque difícilmente puede hacerse 
compatible la idea del buen gobierno con los principios y valores que han de guiar a las cooperativas. A partir de la definición de cooperativa que se recoge en el artículo 1 de la Ley española 27/1999, de 16 de julio, de Cooperativas, -que, por lo demás, es generalmente seguida en la legislación cooperativa de las Comunidades Autónomas españolas- Puentes, Velasco y Vilar (2009, p. 125) no dudan en afirmar que, tras la definición, se esconde el enfoque stakeholders de gobierno corporativo. En él el objetivo último es la satisfacción de los intereses de todos los grupos de interés a partir del cumplimiento de unos principios y labores cooperativos:

La cooperativa es una sociedad constituida por personas que se asocian, en régimen de libre adhesión y baja voluntaria, para la realización de actividades empresariales, encaminadas a satisfacer sus necesidades y aspiraciones económicas y sociales, con estructura y funcionamiento democrático, conforme a los principios formulados por la Alianza Cooperativa Internacional, en los términos resultantes de la presente Ley (art. 1 Ley 27/1999, de 16 de julio, de Cooperativas).

Este enfoque permitía a esos autores concretar, en un cuadro resumen (Puentes, Velasco y Vilar, 2006, p. 136), cuáles de las recomendaciones que en su día se daban en el Código Unificado de Buen Gobierno, aprobado por la Comisión Nacional del Mercado de Valores, de 22 de mayo 2006, podían ser seguidas en la organización y funcionamiento de la Asamblea General, del Consejo Rector y de los Interventores por las sociedades cooperativas y cuáles no.

En esta línea, también, un sector doctrinal viene señalando que el buen gobierno de las cooperativas es el que compatibiliza el máximo nivel de desempeño económico de la sociedad con la preservación o desarrollo de su identidad cooperativa, en particular, el principio democrático de decisión (Villafáñez, 2017 a), p. 63). El alcance de este principio lo destacan Botana (2018, p. 253-254), Barrero y Viguera (2015, pp. 178-182) señalando cuatro aspectos esenciales en los que -según estos autoresse ha de traducir la exigencia democrática: participación activa de los socios en la fijación de las políticas y en la toma de decisiones; responsabilidad ante los socios de quienes resulten elegidos para gestionar y representar a la sociedad; igualdad del derecho de voto en las cooperativas de primer grado; organización democrática en las cooperativas de otros grados.

No obstante, en la literatura cooperativa española, Santos Domínguez (2014, pp. 321 y ss.) recientemente, ha planteado una perspectiva novedosa del gobierno corporativo de la sociedad cooperativa. En ella se parte de la idea de que el poder 
societario en las sociedades cooperativas está delimitado por la mutualidad, mientras que en las sociedades capitalistas el poder tiene como fuente el capital social. Se viene a decir así que, mientras que el método de búsqueda del titular del poder societario en las sociedades capitalistas radica en analizar la relación entre propiedad -titularidad del capital social- y el control -gestión y administración de los asuntos sociales-, en las sociedades cooperativas el método de relación es el mismo, pero el precipitado es distinto: ahora se trataría de una relación entre actividad económica -actividad cooperativizada- y control,

Lo que significa que en las cooperativas las cuestiones relativas al poder societario han de estudiarse en las relaciones entre quienes realizan actividad cooperativizada-socios-y quienes administran la sociedad-socios administradores y directivos-; por ello los planteamientos teóricos sobre el gobierno societario han de basarse en postulados diferentes a los propios de las sociedades cotizadas (pp. 321-322).

Este planteamiento, que sin duda tiene el mérito de destacar el significado de la mutualidad y de la actividad cooperativizada de los socios en la sociedad cooperativa, en nuestra opinión, no deja de ser un planteamiento monista en la solución del gobierno corporativo. En este planteamiento, la posición de los accionistas de las sociedades capitalistas se viene a sustituir por la de los socios que realizan la actividad cooperativa, dejándose fuera la consideración de otros intereses que no deberían -en nuestra opinión- obviarse en la búsqueda del buen gobierno de las sociedades cooperativas. Santos Domínguez considera como elementos identificadores de las cooperativas la mutualidad y la participación orgánica, pero desvincula los principios cooperativos de la configuración tipológica e identitaria de la cooperativa, lo que, evidentemente, le lleva a una peculiar configuración del "interés social", que es el elemento determinante en la teoría del buen gobierno corporativo. A pesar de la rica y extensa argumentación que este autor recoge, la cuestión no dejar de ser controvertida (Villafañez, 2017 b, p. 395), especialmente, por la consideración que se hace de los principios cooperativos.

En nuestra opinión, la idea de buen gobierno de las sociedades cooperativas no puede desvincularse de los principios y valores de las mismas. Fruto de las discusiones, reflexiones y aportaciones sobre el comportamiento ético adecuado que deben llevar a cabo las cooperativas, en la declaración sobre la Identidad Cooperativa de la Alianza Cooperativa Internacional de Manchester de 1995, se formulan los siguientes como valore en los que se basan las cooperativas: "... la autorresponsabilidad, la democracia, la igualdad, la equidad y la solidaridad. Siguiendo -continúa la declaración- la 
tradición de sus fundadores, los socios cooperativos hacen suyos los valores éticos de la honestidad, la transparencia, la responsabilidad y la vocación social". Si ya de por sí el reconocimiento como valores supone su aprecio, su importancia y el motivo de actuaciones para su logro (Salinas, 1995, p. 165), se señalan también las pautas mediante las cuales las cooperativas ponen en práctica esos valores. Esas pautas constituyen en la declaración los principios cooperativos. La doctrina ha destacado la importancia de esta concepción en cuanto aleja la tentación de convertir los principios en un mero desideratum o ideal utópico e inalcanzable. El estudio de esos principios, su estudio, profundización y aplicación se convierte así en un objetivo irrenunciable de las cooperativas y de sus dirigentes. Los socios de las cooperativas, los Consejos Rectores y, en su caso, los Directores de las mismas han de exigir mutuamente el cumplimiento de esos principios y actuar a la luz de los mismos. Los poderes públicos -y especialmente, en ordenamientos que recojan constitucionalmente el fomento del cooperativismo- no podrán permanecer impasibles ante aquella declaración de identidad cooperativa, ahora renovada, de la organización, debiendo verificar si las disposiciones normativas de los Estados son adecuadas o no para el desarrollo libre y eficaz de esos principios (Paz, 1995, pp. 19-20).

La declaración formal de principios de la ACI de 1995 supuso una reformulación de la realizada en 1966, distinguiéndose ahora de los valores, como una manifestación - se ha dicho- del constante movimiento del fenómeno del cooperativismo (Morillas y Feliú, 2002, p. 84). En ella, como es conocido, se enumeraron siete principios: adhesión voluntaria y abierta; gestión democrática por parte de los socios; participación económica de los socios; autonomía e independencia; educación, formación e información; cooperación entre cooperativas; interés por la comunidad. Principios cooperativos que fueron asumidos en la Resolución 56/114, de la Asamblea General de Naciones Unidas de 19 de diciembre de 2001 (puede verse también el informe 2001/68 del Secretario General, de 14 de mayo de 2001), e incorporados en la Recomendación de la Organización Internacional del Trabajo 193, de 20 de junio de 2002. También en la Comunicación de la Comisión Europea (COM (2003)18) al Consejo, al Parlamento Europeo, al Comité Económico y Social Europeo y al Comité de las Regiones, de 23 de febrero de 2004, sobre fomento de las cooperativas en Europa, se viene a decir que la nueva legislación nacional sobre cooperativas debe basarse en la definición, los valores y los principios cooperativos. Aunque se añade: "No obstante, en este contexto los gobiernos deben ser suficientemente flexibles para permitir a las cooperativas competir eficazmente en el mercado en términos de igualdad con otras fórmulas empresariales" (apartado 3.2.4). 
En el documento de Principios de Derecho Cooperativo conocidos como PECOL (Principles of European Cooperative Law), elaborado por un grupo de profesores universitarios expertos en derecho cooperativo (SGECOL, Study Gropup on European Cooperative Law), tras una investigación comparada de la legislación cooperativa y las mejores prácticas de varias jurisdicciones europeas (Fajardo et al. (2018, p. 315 y ss.), en su capítulo II, sobre gobernanza cooperativa, expresamente se recoge que: "La gobernanza cooperativa reflejará su naturaleza mutual, democrática y autónoma y funcionará de acuerdo con los valores y principios cooperativos universalmente reconocidos, incluyendo la responsabilidad social cooperativa".

En fin, los principios cooperativos, toda vez que son incorporados por las leyes de cooperativas, forman parte del derecho positivo. Por ello, la llamada que se hace en las leyes a esos principios no es una simple declaración de intenciones sin concreción normativa real. La doctrina y jurisprudencia españolas han podido defender su carácter de auténticas normas jurídicas, directamente aplicables y, por ello, a las que han de someterse los estatutos y los acuerdos sociales (Alfonso, 2015, p. 60). Los principios y valores cooperativos -se ha dicho también-, se erigen en criterios informadores, no solo de la actuación de los legisladores en materia de cooperativas, sino también de la autonomía de la voluntad de los particulares en orden a establecer nuevos pactos no previstos por la Ley (Alfonso, 2015, pp. 58-59).

\section{EVOLUCIÓN EN ESPAÑA DE LOS MÉTODOS JURÍDICOS PARA EL BUEN GOBIERNO CORPORATIVO.}

Como hemos apuntado, el eje central del gobierno de las corporaciones ha venido siendo el control de los problemas de agencia entre accionistas (principales) y directivos (agentes). La idea predominante de buen gobierno ha venido siendo la de crear valor para los accionistas (principales) y maximizar el precio de sus valores. En torno a este enfoque se han ensayado los métodos e instrumentos técnico-jurídicos para la consecución de los objetivos del buen gobierno. En esa elección, como también anticipamos, no ha dejado de estar latente el dilema intervención legislativa (regulación) versus autorregulación.

La evolución en España podemos estructurarla a lo largo de las tres etapas que seguidamente apuntamos. En todas ellas predomina una concepción financiera de la empresa que mira más a la tutela de los recursos financieros captados en el mercado de capitales que a la producción de bienes y servicios desde una perspectiva 
económico-social más general. En definitiva, el buen gobierno termina siendo la maximización del valor de la empresa, en el que se traduce el interés social. Pero, como nos advierte la doctrina, en las etapas hay una cierta reformulación de esa idea de maximización de valor (Esteban, 2005, pp. 33 y ss.). En esa evolución, tampoco pueden desconocerse algunas consideraciones críticas sobre los límites o insuficiencias de las teorías de la creación de valor como criterio determinante para el buen gobierno de las compañías.

\subsection{Primera etapa: El Código Olivencia.}

En una primera etapa, que se inicia a finales de los años 80 del pasado siglo, el modelo predominante es el modelo anglosajón, basado en las propuestas y recomendaciones elaboradas en lo que se conocen como "Códigos" de buen gobierno, de origen negocial y, en cualquier caso, se asunción voluntaria. En general, los Códigos de buen gobierno pueden definirse como un conjunto de recomendaciones que mejoran el comportamiento de las organizaciones respecto a la transparencia informativa, composición y funcionamiento de los órganos de gobierno y relación con los distintos grupos de interés, cuyo objetivo será dictar las directrices para instaurar un determinado modelo de gobierno corporativo (Puentes Poyatos, R.; Velasco Gámez, Ma M. y Vilar Hernández, J. 2009. p. 126, recogiendo la definición de la Asociación Española de Contabilidad y Auditoría). En esta primera etapa situamos en España el Código de Buen Gobierno, elaborado por la Comisión Especial para el Estudio de un Código Ético de los Consejos de Administración de las Sociedades, creada por acuerdo del Consejo de Ministros, de 28 de febrero de 1997, y presidida por el profesor Manuel Olivencia, que concluyó sus trabajos en lo que se conoce como Informe Olivencia, publicado en febrero de 1998.

\subsection{Segunda etapa: Informe Aldama, Ley de Transparencia y Código Conthe.}

El cambio de siglo vino a coincidir con la crisis en los Estados Unidos del modelo anterior y la reacción legal más exigente, materializada en la Sarbanes Oxley Act de 2002, que no dejó de influir en algunas recomendaciones de las instituciones europeas (Garrido, 2007: 50). A partir de aquí las iniciativas en Europa prefieren combinar el método de la autorregulación con el método legislativo. Significativo de esta etapa es, en la Unión Europea, el Informe (segundo) Winter de noviembre de 2002; donde se sugiere también el uso de los instrumentos normativos. Esta misma línea seguiría. 
por ejemplo, la Comisión Europea en las Recomendaciones sobre consejeros externos y comisiones del Consejo de 15 de febrero de 2005 (2005/162/EC), o sobre retribuciones de consejeros de sociedades cotizadas, de 14 de diciembre de 2004 (2004/91/EC), o, también, en algunas Directivas: 2006/43/CE, de 17 de mayo de 2006 (modificada por la 2008/30/CE, de 11 de marzo); 2006/46/CE, de 14 de junio de 2006; 2007/36/CE de 11 de julio de 2007.

Por lo que concierne al ordenamiento español, de esa etapa también es el conocido como Informe Aldama, elaborado por una Comisión Especial nombrada por Consejo de Ministros por él presidida y publicado en enero de 2003. Interesa de este informe recordar que, aunque no es una norma legal y sus recomendaciones serían asumidas voluntariamente, recalca la necesidad de explicar, en su caso, los motivos por los que la entidad en cuestión se desvía de dichas recomendaciones (principio de "cumplir o explicar"). Al propio tiempo reconoce que existen parcelas donde la autorregulación no es suficiente, siendo necesaria la intervención del legislador (como ocurre con los deberes de fidelidad y lealtad de los administradores).

El informe Aldama, manteniendo la continuidad con el de Olivencia, pero con una visión más realista frente al exceso ideológico liberal, da paso a la intervención explícita del poder legislativo en una serie de cuestiones, que se materializarían en la Ley 26/2003, de 17 de julio, por la que se modifican la Ley 24/1988, de 28 de julio, del Mercado de Valores, y el Texto Refundido de la Ley de Sociedades Anónimas. El fin que se pretende - dice el rótulo de la ley- será el de "de reforzar la transparencia de las sociedades anónimas cotizadas". La intervención legislativa continuó con la aprobación de otras leyes posteriores (Mateu de Ros, 2007, p. 19). Además, conviene precisar que, a pesar del rótulo de aquella ley conocida en el sector como "ley de transparencia", no incide sólo en el principio de la transparencia (imponiendo, además, determinados medios de información) como si fuera la única regla para el logro del buen gobierno corporativo, sino que también incorpora principios éticos y orgánico-funcionales en el buen gobierno societario.

La evolución no se paró ahí. Un acuerdo del Consejo de Ministros de 29 de julio de 2005, encomendó a la Comisión Nacional del Mercado de Valores la unificación y actualización de las recomendaciones sobre gobierno corporativo contenidas en los informes Olivencia y Aldama, teniendo en cuenta las recomendaciones de la Comisión Europea y otras de carácter internacional. El resultado fue el Código Unificado de Buen Gobierno Corporativo, adoptado mediante acuerdo del Consejo de la CNMV, de 22 de mayo de 2006. Acuerdo que había sido elaborado sobre el Informe del Grupo Especial de trabajo sobre buen gobierno de las sociedades cotizadas, que presidió Manuel Conthe. Aunque el grupo de trabajo podía proponer iniciativas o reformas normativas 
complementarias no solo para las sociedades cotizadas sino también para otras empresas, el informe se ciñó a las sociedades cotizadas (Santos, 2014, p. 342). Allí se señalaban las normas jurídicas que regulan, generalmente de forma imperativa, los asuntos relacionados con las materias objeto de Recomendaciones del Código Unificado. Las reformas legales cristalizarían después en el Real Decreto Legislativo 1/2010, de 2 de julio, por el que se aprueba el Texto refundido de la ley de sociedades de capital. Después en la ley 25/2011, de 1 de agosto, de reforma parcial de la ley de sociedades de capital y de incorporación de la Directiva 2007/36/CE, del Parlamento Europeo y del Consejo, de 11 de julio, sobre el ejercicio de determinados derechos de los accionistas de sociedades cotizadas, y en la Ley 31/2014 de 3 de diciembre, por la que se modifica la ley de sociedades de capital para mejora del gobierno corporativo, en la que, por su significación, a continuación nos detenemos.

\subsection{3.- Tercera etapa: La Ley $31 / 2014$ y el Código Rodríguez.}

Los antecedentes de la Ley 31/2014 se encuentran en el informe de la Comisión de Expertos creada mediante Orden ECC/895/2013, de 21 de mayo, sobre buen gobierno de las sociedades en España, publicado cono: "Estudio sobre propuestas de modificaciones normativas en materia de Gobierno Corporativo", presentado el 14 de octubre de 2013. Si bien éste contiene propuestas en materia de gobierno corporativo para todas las sociedades de capital y no solo para las cotizadas (Santos, 2014, p. 343).

Como han señalado los comentaristas, la Ley viene a recoger la preferencia del legislador español por la técnica legislativa, en sentido estricto, frente al solf low que habitualmente se contempla en los códigos de buen gobierno (Embid, 2016, p. 27). Con esa Ley el legislador español opta por la técnica legislativa como técnica jurídica para la mejora del gobierno corporativo, con lo que quedaban superadas muchas de las recomendaciones del Código Unificado de Buen Gobierno de 2013 (versión actualizada del citado de 2006, aprobado también por la CNMV y en el que se habían suprimido las recomendaciones que se habían incorporado a las normas legales).

La doctrina mercantil española resalta los objetivos de la Ley 31/2014: reforzar la estabilidad societaria y dar seguridad al funcionamiento de sus órganos, en particular a los administradores (como se comprueba en lo que se refiere al tratamiento de la impugnación de acuerdos de la junta y, como novedad, en el sistema de protección de la discrecionalidad empresarial, previsto en el artículo 226 LSC). Así también, como se reconoce en la exposición de motivos, el fomento de la participación de los socios en los órganos sociales (p. e. publicaciones en Web, voto a distancia, incluyendo el 
on-line, fraccionamiento del voto en caso de representantes) y la mejor defensa de sus derechos (ampliación a 5 días el ejercicio del derecho de información antes de la junta, información sobre lo que se haya comunicado a la CNMV; publicación de respuestas en la Web, Reglamento de funcionamiento publicado en la Web), además de buscar que la sociedad sea más transparente (como, por ejemplo, con el sistema de remuneraciones de los consejeros).

La citada Comisión de Expertos de 2013, además de proponer las iniciativas y las reformas normativas que se consideraron adecuadas para garantizar el buen gobierno de las empresas -y que darían lugar a la Ley 31/2014- tenía como función prestar apoyo y asesoramiento a la CNMV en la modificación del Código unificado. El nuevo Código de buen gobierno de las sociedades cotizadas, denominado como Código Rodríguez por ser la presidenta de la CNMV Elvira Rodríguez (Olivencia, 2017, p. 340), se aprobó por Acuerdo del Consejo de la CNMV de 18 de febrero de 2015.

Como se ha dicho, el nuevo Código sigue, en lo esencial, el modelo accionarial de gobierno corporativo, basado en la presunta soberanía del accionista (Moreno, 2015). Sim embargo, tampoco pueden negarse ciertos avances hacia un enfoque plural en el gobierno corporativo. Al respecto debe destacarse la incorporación de recomendaciones específicas en materia de responsabilidad social corporativa, que el informe de 19 de mayo de 2006 del Grupo especial de trabajo sobre buen gobierno corporativo de las sociedades cotizadas había excluido expresamente. Así, ahora se reconoce que

la importancia de la responsabilidad social corporativa de la empresa es una realidad cada vez más asentada, tanto en España como en los países de nuestro entorno, que exige una adecuada atención por parte de los sistemas de gobierno corporativo de las sociedades y, por lo tanto, que no puede quedar al margen de un código de recomendaciones de buen gobierno corporativo.

Las recomendaciones del nuevo Código son, evidentemente, de cumplimiento voluntario, pero sigue rigiendo el principio de cumplir o explicar, para el que la CNMV aprobó el 15 de julio de 2016 una "Guía técnica de buenas prácticas para la aplicación del principio "cumplir o explica" (Fernández, 2017, p. 511). Como Principios de aspecto general, el Código recoge, además del deber de informar con claridad en la junta general sobre el grado de cumplimiento de las recomendaciones, el que la sociedad cuente con una política pública de comunicación y contactos con accionistas, inversores institucionales y asesores de voto. La junta general debe funcionar bajo principios de 
transparencia e información adecuada, debe facilitarse la asistencia y participación y debe haber transparencia en las primas de asistencia.

Del Consejo de Administración, expresamente se dice "asumirá, colectiva y unitariamente, la responsabilidad directa sobre la administración social y la supervisión de la dirección de la sociedad, con el propósito común de promover el interés social". Tendrá una dimensión precisa para favorecer su eficaz funcionamiento, la participación de todos los consejeros y la agilidad en la toma de decisiones. La política de selección de consejeros promoverá la diversidad de conocimientos, experiencias y género en su composición ( $y$, en concreto, se recomienda que la política de selección de consejeros promueva el objetivo de que en el año 2020 el número de consejeras represente, al menos, el 30\% del total de miembros del consejo de administración). El Consejo tendrá una composición equilibrada, con una amplia mayoría de consejeros no ejecutivos y una adecuada proporción entre consejeros dominicales e independientes, representando estos últimos, con carácter general, al menos la mitad de los consejeros. Las causas de separación y dimisión de los consejeros no condicionarán su libertad de criterio, protegerán la reputación y crédito de la sociedad (se recomienda, en concreto, que las sociedades establezcan reglas que obliguen a los consejeros a informar $y$, en su caso, a dimitir en aquellos supuestos que puedan perjudicar al crédito y reputación de la sociedad). El consejo evaluará periódicamente su desempeño y el de sus miembros y comisiones. Se establecen una serie de garantías y recomendaciones en el nombramiento, composición y funciones de las comisiones de Nombramientos, Retribuciones, y Auditoría.

En las Recomendaciones concretas sobre responsabilidad social se recoge que la política de responsabilidad social corporativa incluya los principios o compromisos que la empresa asuma voluntariamente en su relación con los distintos grupos de interés e identifique, al menos, lo siguiente: Ios objetivos de la política de responsabilidad social corporativa y el desarrollo de instrumentos de apoyo; la estrategia corporativa relacionada con la sostenibilidad, el medio ambiente y las cuestiones sociales; las prácticas concretas en cuestiones relacionadas con accionistas, empleados, clientes, proveedores, cuestiones sociales, medio ambiente, diversidad, responsabilidad fiscal, respeto de los derechos humanos y prevención de conductas ilegales; los métodos o sistemas de seguimiento de los resultados de la aplicación de las prácticas concretas señaladas anteriormente, los riesgos asociados y su gestión; los mecanismos de supervisión del riesgo no financiero, la ética y la conducta empresarial; los canales de comunicación, participación y diálogo con los grupos de interés; las prácticas de comunicación responsable que eviten la manipulación informativa y protejan la integridad y el honor. 
En fin, en la Recomendación 55 se indica que la sociedad informe, en un documento separado o en el informe de gestión, sobre los asuntos relacionados con la responsabilidad social corporativa, utilizando para ello alguna de las metodologías aceptadas internacionalmente.

\subsection{Colofón: La transparencia como principio rector del gobierno de las sociedades.}

El resultado de todo este proceso en el reconocimiento del buen gobierno corporativo parece confirmar la existencia de un criterio mixto a la hora de ordenar la realidad del gobierno corporativo, que supone la necesaria y simultánea presencia tanto de la vertiente legislativa como de la basada en la autorregulación. Con todo, como nos advierte la doctrina española, este criterio no ha de entenderse desde una perspectiva igualitaria, como si ambas vertientes concurrieran en un plano de equilibrio a la ordenación del gobierno corporativo (Embid, 2013, p. 73). Si en épocas inmediatamente anteriores a la crisis económica de 2008 la idea del Código de buen gobierno parecía, a los ojos de un nutrido grupo de autores, suficiente para "ordenar" los problemas derivados de la materia de estudio, sin embargo, con posterioridad se ha afianzado el método regulador, al menos, como propósito.

De una manera u otra lo que no ofrece duda a los autores es que la transparencia es el principio fundamental en el gobierno de las sociedades, incluso, para algunos, el único principio a considerar en el modelo de buen gobierno corporativo. La posición de la Unión Europea en esta materia está basada, sustancialmente, en la transparencia, como técnica básica de regulación. Sustanciándose esta transparencia, fundamentalmente, en la obligatoriedad de la publicación del informe anual de gobierno corporativo con el concurso del principio "cumplir o explicar", a fin de que pueda valorarse el seguimiento de los códigos de buen gobierno que procedan en cada Estado miembro. Con todo, no han faltado, tampoco, normas concretas, como las que antes indicábamos, que van más allá de una orientación basada en la transparencia (Garrido, 2007, p. 74).

Esa transparencia que se reclama en el buen gobierno de las sociedades privadas capitalistas, no parece que tenga que ser menos exigente para el buen gobierno de las sociedades cooperativas. Desde un análisis más general, que se extiende a todas las entidades no lucrativas, se ha podido decir que

la supervivencia y garantía de calidad de muchas organizaciones no lucrativas dependerán del uso de la transparencia como valor en su 
comportamiento diario. Y además, dependerá de cómo fomenten y comuniquen ese valor a todo el conjunto de públicos de dentro y fuera de la organización... la transparencia de ha convertido en un valor central dentro de una sociedad que camina entre problemas que acrecientan la inseguridad, la incertidumbre y la desconfianza de los ciudadanos ( $\mathrm{He}$ rranz, 2007, p. 8).

Esta transparencia, que se viene afianzando como un valor en los gobiernos de las empresas, resulta aún más importante en las entidades de economía social. En las entidades y organizaciones de empresas de estos sectores "es cada vez mayor la obligación de pensar en cómo mejorar la transparencia para afianzar la confianza y la reputación de los distintos grupos de interés" (Herranz, 2007, p. 21).

Nadie pone en duda que el objetivo de la transparencia y fluidez de las relaciones de la empresa es un objetivo conveniente y útil para el buen gobierno de las mismas. Ahora bien, la transparencia que se reclama, no puede quedar reducida a una publicidad documental meramente formal, porque la verdadera transparencia exige una información con garantías de calidad; y por ello ha de ser completa, correcta, equitativa, simétrica, oportuna. Así se venía a decir en el Informe Aldama y así se recoge en la doctrina científica (Mateu de Ros, 2004, p. 32 y referencias allí citadas). Más allá de la mera rendición de cuentas -se ha venido a decir también para las entidades no lucrativas- la transparencia ha de implicar un comportamiento comunicativo que alcance áreas como administración y finanzas; organización y dirección; ética y responsabilidad social; comunicación; ideología; participación (Herranz, 2007, 27).

Recobrará así interés el análisis de las distintas medidas que se han venido adoptando en los ordenamientos en aras al logro de la transparencia, que, si bien están pensadas para las sociedades cotizadas, resulten extensibles, mutatis mutandis, a las sociedades cooperativas. En esa labor de política jurídica en materia de cooperativas, nuestros legisladores deberían valorar la posible conveniencia de la exigibilidad legal de una transparencia (externa e interna) a través de los distintos medios de información (donde, sin duda, las nuevas Técnicas de Información y Comunicación -TIC- se nos ofrecen como un buen recurso). Entre esos medios de información no habrá que descartar, en función de la dimensión o integración cooperativa, la pertinencia de la elaboración y difusión de Informes de gobierno corporativo, que permitan contrastar el grado de seguimiento de las reglas o recomendaciones de los códigos de gobierno corporativo.

No obstante, como también se ha señalado, la transparencia no es la única regla para el logro del buen gobierno corporativo. Éste exige también la incorporación 
de principios éticos y orgánico-funcionales que garanticen el cumplimiento de la información veraz y la diligencia y lealtad de los administradores. Es decir, los principios de transparencia y de ética de conduzca, se completan con una serie de principios de eficacia organizativa que resultan igualmente necesarios para el logro del buen gobierno societario (Mateu de Ros, 2004, p. 31). Separación y equilibrio de poderes; reforzamiento de los sistemas de control interno y externo; regulación de los deberes de fidelidad y lealtad del Consejo Rector y directivos, y consecuente responsabilidad, son todas cuestiones que en materia de cooperativas han de ser valoradas y clarificadas por el legislador. Resolviéndose a la vez, por ejemplo, las incertidumbres que, en particular, las leyes de cooperativas españolas generan con remisiones genéricas a las sociedades anónimas en temas como el de responsabilidad de administradores (Pastor, 2007).

\section{ALGUNAS PROPUESTAS Y RECOMENDACIONES DE BUEN GOBIERNO PARA LAS COOPERATIVAS EN ESPAÑA.}

Anticipamos ya cómo algunos autores (Puentes, Velasco, Vilar, 2009), desde un enfoque Stakeholders y tomando en consideración el Código unificado de buen gobierno existente en esa época, deslindaron las posibilidades de seguimiento de las Recomendaciones de ese Código a las sociedades cooperativas. Particularmente, en lo que se refiere a la organización y funcionamiento de la Asamblea General, donde se propugna la limitación al voto plural y se postula la posibilidad del voto fraccionado, así como en la organización del Consejo Rector (no considerando necesaria la incorporación de independientes), y en la de los Interventores de las cooperativas (que se equiparan, como órgano, al Comité de Auditoría de las sociedades de capital). Considerando, también, el régimen de incompatibilidades de cargos como un mecanismo de control propio de las cooperativas.

En la monografía de Santos Domínguez publicada en diciembre de 2014, que más arriba citamos, partiendo de la idea de que las cooperativas deben adoptar instrumentos de gobierno corporativo teniendo en cuenta sus características particulares (tamaño, clase de actividad y estructura), se analiza el papel y el régimen de la Asamblea General, se defiende y potencia su papel decisorio y de control como sede adecuada para solucionar problemas de gobierno y se apuesta por la sociedad 
cooperativa de segundo y ulterior grado como instrumento de gobierno corporativo que puede facilitar la participación orgánica de las socias. Lo controvertido de alguna de sus propuestas no desmerece el cuidadoso y detallado análisis jurídico que nos presenta.

Mención especial merece el "Código de Buen Gobierno de las Cooperativas" elaborado por la Confederación de Cooperativas de Euskadi (KONFECOOP) y la Federación de Cooperativas de Trabajo Asociado, Enseñanza y Crédito de Euskadi (ERKIDE) en 2011. El documento, que como se dice ya en su Prólogo, está destinado a las cooperativas de Euskadi, recoge los valores y normas de comportamiento ético que deben guiar en la toma de decisiones, tanto en las tareas de gobierno interno (órganos sociales, órganos directivos y de gestión, socios/as), como en las relaciones con los grupos de interés (Trabajadores, clientes, proveedores, instituciones y la sociedad en general).

Afirmando que los valores y principios básicos de las cooperativas deben determinar los comportamientos de las organizaciones y de las personas y, en particular, de los Órganos sociales y Directivos, el referido Código se estructura en cuatro objetivos básicos: Órganos sociales (donde se explicitan y desarrollan valores y comportamientos de la Asamblea general, Consejo Rector, Comisión de Vigilancia...); Órganos directivos y de gestión (se concretan líneas de comportamiento, compromisos con la cooperativa y su desarrollo); socios y socias (comportamientos exigidos, implicación con los objetivos; relaciones internas); y la propia cooperativa en sus relaciones con sus grupos de interés (líneas de comportamiento, valores, responsabilidad social).

Por su parte, el documento de Principios de Derecho Cooperativo conocidos como PECOL, publicado en 2017, sobre el que ya hicimos referencia, recoge como principios generales de la gobernanza cooperativa (Capítulo II, Sección 2.1) la necesidad de reflejar "su naturaleza mutual, democrática y autónoma" y de funcionar "de acuerdo con los valores y principios cooperativos universalmente reconocidos, incluyendo la responsabilidad social cooperativa", así como que la estructura de la gobernanza asegure su autonomía y control por parte de sus miembros (Fajardo et al. 2018, p. 323 y ss.). Pero, además, se recogen, como obligaciones de los miembros de la cooperativa, la de prestar "un nivel mínimo de participación en la gobernanza de la cooperativa" (Sección 2.3 c) y, aunque referidos a las cooperativas de interés general, el que los estatutos especifiquen las obligaciones y derechos de sus miembros cooperativistas o no- "incluyendo las diferentes atribuciones a los diversos grupos en la consecución del interés general de la comunidad".

En los derechos individuales de los cooperativistas (Sección 2.3. 4) aparecen los siguientes principios: participar en las actividades de educación y formación 
cooperativa; participar en la gobernanza de su cooperativa asistiendo y participando activamente en las reuniones, de forma personal y directa o mediante representante; votar en las elecciones a miembros de los órganos o en cualquier asunto decidido por votación directa de los miembros (presencialmente, electrónicamente, o por correo); presentarse como candidato a elecciones; solicitar y recibir información, incluida la información financiera.

Como derechos colectivos (Sección 2.3,5) se recogen los siguientes: recibir o solicitar información; proponer candidatos para ser elegidos como administradores o delegados en otros órganos o asambleas; solicitar la convocatoria de una asamblea general; hacer propuestas de acuerdos o añadir temas al orden del día de una asamblea general; exigir una auditoría de la cooperativa.

En la configuración de la estructura de gobernanza cooperativa (Sección 2.4) se busca garantizar el control democrático por sus miembros. En las cooperativas pequeñas salvo que los estatutos indiquen lo contrario, todos los miembros participarán directamente en la toma de cada decisión y, en las demás cooperativas, la gobernanza se dividirá entre una estructura u órgano que permita a los miembros el control final de la organización (la asamblea general) y uno o más órganos o comisiones, responsables de la gestión diaria de la cooperativa y que responderán ante los miembros. La asamblea general puede delegar funciones; podrá ser organizada como una única asamblea o varias asambleas separadas y, en cooperativas con numerosos miembros, los estatutos de las cooperativas podrán prever reuniones sectoriales. Estas reuniones podrán ser presenciales o virtuales. La asamblea general tiene competencias para nombrar y destituir a los administradores y deberá tener competencias para tomar las decisiones fundamentales. En el apartado 6 se detallan también las funciones de asamblea general.

En las votaciones, se parte de la regla de un miembro un voto, con independencia del capital aportado. Si bien, cuando sea necesario para un mejor funcionamiento de la cooperativa, los estatutos podrán atribuir votos plurales no relacionados con la aportación a capital (Sección 2.4 (7), garantizándose que, en ningún caso, los inversores o una minoría sean la que controle la cooperativa y estableciéndose ciertos límites (Sección 2.4 (10).

En fin, en cuanto a la asamblea general, se procuran unas adecuadas convocatorias (ordinarias y extraordinarias) y una adecuada constitución. Se propugnan regímenes de mayorías simple y cualificada y, en las cooperativas con numerosos miembros, se prevé la elección de un órgano de menor dimensión que desempeñe las funciones de supervisión y control del órgano de administración en un sistema monista. 
En cuanto a la administración y control interno (Sección 2.5), se atribuye al órgano de administración, en las cooperativas que lo tengan, las funciones de gestión, representación y supervisión. Se contempla la posibilidad de los sistemas monista y dualista en el consejo de administración. Las facultades de representación y gestión de la cooperativa serán atribuidas a un consejo rector en el sistema monista o a un consejo de dirección en el sistema dual, o a uno o más administradores, pudiendo, en cualquier caso delegarse (Sección 2. 5 (3). La supervisión se centra en el desarrollo económico y social de la cooperativa y conlleva la supervisión y control de los directores o gerentes, contactando, en su caso, con los auditores externos. Se contempla que la mayoría de los miembros de los órganos de administración y supervisión sean cooperativistas (Sección. 2.5 (6) y que la ley o los estatutos establezcan lo siguiente: número máximo y mínimo de cada órgano, duración y número de mandatos; condiciones en cuanto a la paridad de género; procedimientos de designación o elección; requisitos necesarios para ser miembros del órgano de administración y las causas para su destitución (Sección. 2.5 (7). En los deberes de los administradores y directivos de la cooperativa se "incluyen la obligación de adhesión a los valores, principios y prácticas características de las cooperativas, además de la obligación de cumplir la ley y los estatutos de la cooperativa y sus deberes de honestidad, lealtad, buena fe, diligencia y competencia" (Sección. 2.5 (8).

La Sección 6.2, bajo la rúbrica de Derechos de información de los miembros y requisitos de transparencia, se requiere de los administradores y directores que se aseguren de que la cooperativa opere con un alto nivel de transparencia y provea a los miembros de información suficientemente clara para permitirles el control de la cooperativa. En particular, se asegurarán de que se elaboren, auditen y pongan a disposición de los miembros las cuentas anuales y en su caso las cuentas consolidadas, junto con el informe anual de gestión y los informes de auditoría financiera y cooperativa, conforme a la ley. Estos documentos deben estar disponibles para su consulta en el domicilio social de la cooperativa a un precio que no supere el coste del servicio.

El Capítulo IV de PECOL lo dedica a la auditoría de la cooperativa. Como principios generales (Sección 4.1) se establecen la obligatoriedad y condiciones de la auditoría de las cooperativas y se indica que ésta "tiene por objetivo verificar que las cooperativas persiguen sus objetivos definidos en la ley y en sus estatutos, de acuerdo con la sección 1.1, y que su estructura y actividad es consecuente con su identidad en cuanto cooperativas". La Sección 4.2 se ocupa de concretar el ámbito y modalidades de auditoría. Es de destacar que en su ámbito se incluya "...el control democrático de la cooperativa por sus miembros... la sostenibilidad económica de la empresa; la existencia de prácticas de cooperación entre cooperativas y de responsabilidad 
social cooperativa; el nivel de participación en actividades de formación y educación cooperativa; el modo en que el interés general ha sido perseguido y la participación de los interesados en las cooperativas de interés general". En fin, la Sección 4.3, la dedica a la entidad auditora y auditores, y la Sección 4.4 al informe de auditoría.

\section{CONCLUSIONES.}

Las sociedades cooperativas no pueden permanecer al margen de las exigencias de buen gobierno corporativo que se reclaman en el ámbito del sector privado capitalista. Las sociedades cooperativas, como apuntan algunos autores, padecen, también y con frecuencia, deficiencias en el funcionamiento del gobierno corporativo.

Las propuestas sobre el gobierno corporativo (corporate governance) que se han venido haciendo en los últimos años, aunque han estado centradas, básicamente, en el gobierno de las sociedades cotizadas, constituyen un buen punto de referencia para abordar el buen gobierno de las sociedades cooperativas. Ahora bien, el modelo de ese buen gobierno no puede ser ya el modelo accionarial o financiero que busca la maximización del valor de la empresa para los accionistas o propietarios, sino que ha de ser un modelo de gobierno corporativo plural (stakeholders), moderno y participativo, que tenga en consideración los distintos grupos de interés implicados en la actuación y vida de la cooperativa. Es este el modelo que, necesariamente, han de seguir las sociedades cooperativas, toda vez que es el que se corresponde con la identidad, principios y valores que deben guiar a estas entidades.

Todo parece indicar que en el sistema o modelo regulatorio que busque ese buen gobierno, tendrán que convivir los preceptos legales imperativos y las recomendaciones sistematizadas a través de lo que se conoce como Códigos de buen gobierno, de asunción voluntaria, pero guiados siempre por el principio "cumplir o explicar".

En cualquier caso, tampoco se trata de trasladar, pura y simplemente, al ámbito de las sociedades cooperativas ni las normas legales imperativas ni las recomendaciones de los Códigos de buen gobierno, que, en general, están destinadas para las sociedades de capital, sino que, sin desconocer los puntos básicos comunes en el logro del buen gobierno corporativo, ofrezcamos respuestas específicas para el caso las cooperativas, preservando y fortaleciendo la identidad cooperativa.

La reforma española de la Ley de Sociedades de Capital, producida por la Ley $31 / 2014$, concreta cambios relevantes para las sociedades de capital y, en particular, para las sociedades cotizadas. Por su parte, el nuevo Código de Buen Gobierno de las Sociedades Cotizadas, aprobado por la CNMV en febrero de 2015 , no recoge referencias específicas a una posible extensión a sociedades no cotizadas. Sin embargo, ambos 
textos están sirviendo de modelos para formular propuestas de buen gobierno corporativo para entidades no cotizadas, como son los casos de la Guía de Buen Gobierno para empresas pequeñas y medianas, elaborada por Comité de Responsabilidad Social Corporativa e Informes Integrados del REA+REGA Auditores del Consejo General de Economistas (2018) o del Código de Buen Gobierno de las Cooperativas, presentado por la Confederación de Cooperativas de Euskadi (KONFECOOP) y Federación de Cooperativas de Trabajo Asociado, Enseñanza y Crédito de Euskadi (ERKIDE), en 2011.

Todos estos datos, contrastados con la labor desarrollada en el sector cooperativista y, en particular, con el trabajo que recoge los Principios del Derecho Cooperativo Europeo, elaborado por el SGECOL, conocidos como PECOL, constituyen un buen material para afrontar el estudio y formulación de propuestas de mejora de gobierno corporativo para la sociedad cooperativa. La intervención legislativa en España se antoja más compleja, dada la proliferación de normas legales autonómicas de cooperativas que, en este aspecto, también, reclamarían de una conveniente ley de armonización al amparo del artículo 150.3 de la Constitución Española. Sin embargo, la formulación de Códigos de buen gobierno de sociedades cooperativas resulta, por el momento, más viable y operativa. Es la tarea que le corresponde ahora afrontar al sector cooperativista.

\section{REFERENCIAS BIBLIOGRÁFICAS.}

Alfonso Sánchez, R. (2015). Los principios cooperativos como principios configuradores de la forma social cooperativa. CIRIEC-España. Revista jurídica de Economía Social y Cooperativa, Monográfico Principios y valores cooperativos, 27, 49-85.

Banco Central Europeo (2005). Informe anual 2004. Recuperado de https://www.ecb.europa.eu/ pub/pdf/annrep/ar2004es.pdf?f0ccbb47698a052a9dffa32002e1dc3e

Barrero Rodríguez, E. y Viguera Revuelta, R. (2015). El principio de gestión democrática en las sociedades cooperativas. Alcance y recepción legal. CIRIEC-España Revista Jurídica de Economía Social y Cooperativa, 27, 175-203.

Botana Agra, M. (2018) Notas sobre los Códigos de buen gobierno corporativo en el ámbito de las sociedades cooperativas, en Ángel Fernández-Albor Baltar y Elena F. Pérez Carrillo (Dirs.) Marcos R. Torres Carlos (coord..). Actores, actuaciones y controles del buen gobierno societario y financiero (pp. 247-259). Madrid. Marcial Pons. 
Buendía Martínez, I. (2000). La participación democrática: ¿un valor en extinción en las sociedades cooperativas?. Revista de Economía Pública, Social y Cooperativa, CIRIEC-España, 34, 7-22.

Chaves Ávila, R. (2004 a). Gobierno y democracia en la economía social. En Juliá Igual, J. F. (Coor.). Economía social. La actividad económica al servicio de las personas (pp. 35-51). Almería: Caja Rural Intermediterránea. Cajamar.

Chaves Ávila, R. (2004 b). En R. Chaves Ávila, y F. Soler Tormo, f. (2004). El gobierno de las cooperativas de crédito (pp. 17-44). Valencia: CIRIEC-España.

Chaves Ávila, Ry Schediwy, R. (2004). Gobierno, democracia y directivos en las empresas cooperativas. CIRIEC-España, Revista de Economía Pública, Social y Cooperativa, 48, 5-10.

Comisión de Expertos sobre buen gobierno de las sociedades en España. (2014). Estudio sobre propuestas de modificaciones normativas elaborado por la Comisión de Expertos en Materia de Gobierno Corporativo. Revista de derecho bancario y bursátil, 133, 179-232.

Comité de Responsabilidad Social Corporativa e Informes Integrados del REA+REGA Auditores del Consejo General de Economistas (2018). Guía de Buen Gobierno para empresas pequeñas y medianas. Consejo General de Economistas. CEPYME Recuperado de http://www.cepyme. es/wp-content/uploads/2018/02/Gu\%C3\%ADa-Buen-Gobierno-Pymes.pdf

Confederación de Cooperativas de Euskadi (KONFECOOP) y Federación de Cooperativas de Trabajo Asociado, Enseñanza y Crédito de Euskadi (ERKIDE) (2011). Código de Buen Gobierno de las Cooperativas. https://www.konfekoop.coop/fitxategiak/Argitalpenak\%20-\%20 Publicaciones/CBGC.pdf

Cuervo, A, (2004). El gobierno de la empresa. Un problema de conflicto de intereses. En Bueno Campos, E. (Dir). El gobierno de la empresa: en busca de la transparencia y la confianza (pp. 115-135). Madrid: Editorial Pirámide,

Embid Irujo, J. M. (2013). Sobre el derecho de sociedades de nuestro tiempo. Crisis económica y ordenamiento societario, Granada: Editorial Comares.

Embid Irujo, J. M. (2016). Aproximación al significado de la Ley 31/2014, d e3 de diciembre, para la mejora del gobierno corporativo. En A. Emparanza Sobejano. Las nuevas obligaciones de los administradores en el gobierno corporativo de las sociedades de capital (pp. 17-55). Madrid: Marcial Pons. 
Emparanza Sobejano, A. (2012). El gobierno de las entidades público-privadas: las reglas de buen gobierno como mecanismo de transparencia y control. En A. Emparanza Sobejano y José Miguel Embid Irujo (Dirs.). El gobierno y la gestión de las entidades no lucrativas público-privadas (pp. 163-183). Madrid: Marcial Pons.

Esteban Velasco, G. (2005). Interés social, buen gobierno y responsabilidad social corporativa (algunas consideraciones desde una perspectiva jurídico-sociataria). En Gaudencio Esteban Velasco, José María Gondra, José Mariano Moneva Abadía y Pedro Rivero Torre. Responsabilidad social corporativa. Aspectosjurídico-económicos (pp. 13-62). Castelló de la Plana: Publicacions de la Univesitat Jaume I.

Fajardo, G.; Fici, A.; Henrÿ, H.; Hiez, D.; Meira, D. Münkner, H. y Snaith, I. (2017). The Principles of European Cooperative Law according to SGECOL. Los Principios del Derecho Cooperativo según SGECOL. CIRIEC-España. Revista jurídica de Economía Social y Cooperativa, 30, pp. 314-351.

Farrando Miguel, I. (2006). Una aproximación al "Buen Gobierno" de las sociedades anónimas abiertas. Revista de Derecho de Sociedades, 26, 157-202.

Fernández de la Gándara, L (2017). Gobierno corporativo y seguridad jurídica: una contribución al estudio del mercado global en el ámbito societario. En J. Juste y C. Espín (coors). Estudios sobre órganos de las sociedades de capital (vol. II, pp. 465-526). Cizur Menor (Navarra): Thomson Reuters

García Álvarez, B. (2012). Los Códigos de buen gobierno corporativo en las fundaciones. En Alberto Emparanza Sobejano y José Miguel Embid Irujo (Dirs.). El gobierno y la gestión de las entidades no lucrativas público-privadas. (pp. 185-214). Madrid: Marcial Pons.

Garicano Rojas, T y Hafner, P. (2016) Recomendaciones de Buen Gobierno Corporativo para empresas no cotizadas. Centro de Buen Gobierno Recuperado de https://centrobuengobierno.ie.edu/wp-content/uploads/sites/87/2013/11/Recomendaciones-Buen-GobiernoEmpresas-No-Cotizadas.pdf

Garrido García, J. Ma . (2007). El buen gobierno de las sociedades cotizadas: una perspectiva europea. Revista de Derecho del Mercado de Valores, 1, 39-74.

Herranz de la Casa, J. Ma . (2007). La gestión de la comunicación como elemento generador de transparencia en las organizaciones no lucrativas. CIRIEC-España, Revista de Economía Pública, Socialy Cooperativa, 57, 5-31. 
Lizcano, J. L. (2006). Buen gobierno y responsabilidad social corporativa. Partida Doble, 182, 20-35 Recuperado de http://aeca.es/old/comisiones/rsc/partidadoble_buen_gobierno.pdf

Libro Verde sobre normativa de gobierno corporativo de la Unión Europea, de 5 de abril de 2011, Recuperado de : http://ec.europa.eu/internal_market/company/docs/modern/ com2011-164_es.pdf

Mateu de Ros Cerezo, R. (2004). La Ley de transparencia de las Sociedades Anónimas Cotizadas. Elcano (Navarra): Thomson-Civitas.

Mateu de Ros Cerezo, R. (2007). El Código Unificado de Gobierno Corporativo, Elcano (Navarra): Thomson-Aranzadi.

Montalenti, P. (2015). Sociedades cotizadas, mercados financieros y relaciones con los inversores. Revista de Derecho de Sociedades, 44,

Moreno, J. A. (2015). Ante el nuevo Código de Buen Gobierno: más allá de la Economía. Recuperado de http://ecosfron.org/ante-el-nuevo-codigo-de-buen-gobierno-mas-alla-de-la-economia/

Morillas Jarillo. Ma J. y Feliú Rey, M. I. (2002). Curso de Cooperativas. Madrid: Tecnos, $2^{\text {a Ed. }}$

Mozas Moral, A., Moyano Fuentes, J., Senise Barrio, O., Parras Rosa, M., Murgado Armenteros, E. Mª (2005). Cultura cooperativa y eficiencia empresarial: una contrastación en el cooperativismo oleícola. REVESCO. Revista de Estudios Cooperativos, 85, 41-60.

Organización para la Cooperación y el Desarrollo Económicos (OCDE) (2017), Principes de gouvernance d'entreprise du G20 et de l'OCDE, París: Éditions OCDE, http://dx.doi. org/10.1787/9789264269514-fr

Organización para la Cooperación y el Desarrollo Económicos (OCDE) (2004) Principios de Gobierno corporativo de la OCDE. Traducido de la versión original en inglés publicada con el título: OECD Principles of Corporate Governance 2004. París. https://www.oecd.org/daf/ca/corporategovernanceprinciples/37191543.pdf

Olivencia Ruiz, M. (2017). El consejero coordinador. En J. Juste y C. Espín (coors). Estudios sobre órganos de las sociedades de capital (vol. II, pp. 335-351). Cizur Menor (Navarra): Thomson Reuters. 